\title{
Electron impact ionization and cationic fragmentation of the pyridazine molecules ${ }^{\star}$
}

\author{
Marcin Dampc ${ }^{1}$, Paweł Możejko ${ }^{2, a}$, and Mariusz Zubek ${ }^{3, b}$ \\ ${ }^{1}$ Department of Physics of Electronic Phenomena, Faculty of Applied Physics and Mathematics, Gdańsk University \\ of Technology, 80-233 Gdańsk, Poland \\ 2 Department of Atomic, Molecular and Optical Physics, Faculty of Applied Physics and Mathematics, Gdańsk \\ University of Technology, 80-233 Gdańsk, Poland \\ ${ }^{3}$ Department of Control and Power Engineering, Faculty of Ocean Engineering and Ship Technology, Gdańsk \\ University of Technology, 80-233 Gdańsk, Poland
}

Received 7 September 2018 / Received in final form 27 September 2018

Published online 18 December 2018

(C) The Author(s) 2018. This article is published with open access at Springerlink.com

\begin{abstract}
Electron impact mass spectroscopy was used to investigate ionization and cationic fragmentation of the pyridazine (1,2 diazine), $\mathrm{C}_{4} \mathrm{H}_{4} \mathrm{~N}_{2}$, molecules in the gas phase. The mass spectra were measured and the observed mass peaks assigned to the corresponding cations. The appearance energies of most of the cationic fragments were determined and the possible fragmentation processes are discussed. The total cross section for electron impact ionization of pyridazine was calculated using the binary-encounter-Bethe (BEB) model. The calculated cross section was applied to normalize the measured cation yield curves and total and partial cross sections for ionization and cationic fragmentation were obtained over the energy range from the respective ionization thresholds to $140 \mathrm{eV}$.
\end{abstract}

\section{Introduction}

In our recent work, we investigated electron impact ionization and cationic fragmentation of pyrimidine, $\mathrm{C}_{4} \mathrm{H}_{4} \mathrm{~N}_{2}$, molecules by mass spectroscopy in the energy range from the ionization threshold up to $150 \mathrm{eV}$ [1]. Pyrimidine (1,3-diazine) is a six-membered, aromatic heterocyclic molecule, in which two $\mathrm{CH}$ groups of the benzene molecule are replaced by nitrogen atoms at positions (1) and (3) of the ring (Fig. 1). Pyrimidine is isoelectronic with benzene and preserves the planar geometry. The nitrogen atoms give rise to two non-bonding $\left(n_{\mathrm{N}}\right)$ orbitals of the lone-pair electrons [2] and a permanent dipole moment. In studies of ionizing radiation damage to biological tissue in cancer radiotherapy, pyrimidine has been widely accepted as a precursor/analogue of the nucleic bases, cytosine, thymine and uracil, which are the structural units of DNA and RNA. Therefore, pyrimidine has been extensively investigated by electron collisions to build a set of recommended electron impact cross sections. These provide a database for Monte Carlo modelling of the behaviour

\footnotetext{
* Contribution to the Topical Issue "Many Particle Spectroscopy of Atoms, Molecules, Clusters and Surfaces", edited by Károly Tőkési, Béla Paripás, Gábor Pszota, and Andrey V. Solov'yov.

${ }^{a}$ e-mail: paw@pg.edu.pl

b e-mail: marzubek@pg.edu.pl
}

of low energy secondary electrons in the biological environment $[3,4]$. In this context, ionization of pyrimidine and the subsequent fragmentation of its cations and the formation of radicals have been investigated to identify processes, which may lead to the destruction of the pyrimidine molecule. An understanding of these fragmentation processes may then be applied to the nucleic bases, giving insight into bond breaking in the DNA polynucleotide strands.

In the current work, we report studies of the ionization and cationic fragmentation of the pyridazine, $\mathrm{C}_{4} \mathrm{H}_{4} \mathrm{~N}_{2}$, molecules by electron impact in the energy range from ionization threshold up to $140 \mathrm{eV}$. Pyridazine (1,2-diazine) is acyclic isomer of pyrimidine, but now the two nitrogen atoms of the molecule are adjacent to each other in the ring at positions (1) and (2). Figure 1 shows one of the two canonic forms of the resonance hybrid of pyridazine, which has single $\mathrm{N}(1)-\mathrm{N}(2)$ and double $\mathrm{C}(4)=\mathrm{C}(5)$ bonds and has a greater contribution into the structure of the pyridazine molecules [5]. The aims of this work were to provide data for comparison with the corresponding results for pyrimidine ionization and to draw attention to similarities and differences in the cationic fragmentation of both molecules. Thus, we expect that the differing nitrogen atom positions in the two molecular rings will cause differences in the efficiencies of the fragmentation channels, e.g. of the $\mathrm{N}_{2}^{+}$cations, and the corresponding threshold appearance energies (AEs). In the VUV photoionization studies of three nitroimidazole isomers (used 


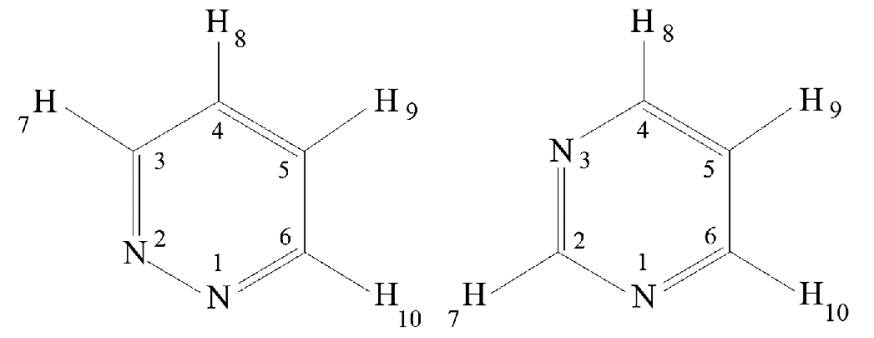

Pyridazine Pyrimidine

Fig. 1. Diagrams of pyridazine and pyrimidine molecules showing labelling of the atoms.

as radiosensitizers in radiotherapy), isomeric effects in the efficiencies and occurrence of decomposition channels of five-membered molecular ring was observed and correlated with position of the nitro $\mathrm{NO}_{2}$ side-group [6].

Apart from being an isomer of pyrimidine, pyridazine is also investigated because its derivatives have been found to possess biological applications. The pyridazine-based compounds have shown various potential pharmacological applications, e.g., as cardiotonic, antidepressant and antihypertensive agents (see review in Ref. [7]). In addition, the newly developed pyridazine derivatives displayed exceptional in vitro antibacterial and antifungal behavior [8]. Moreover, the recently invented pyridazine-related Mps1 kinase inhibitor has remarkable properties in its activity in the tissue cancer cells [9] and the PIM 1 kinase inhibitor was investigated as a novel drug to regulate radiosensitivity in cancer therapy [10].

The mass spectra of gas phase pyridazine have been investigated less frequently than those of pyrimidine. Electron impact induced mass spectra were reported in the mid-1960s and early 1970s [11-14]. High mass resolution measurements, using double focusing mass spectrometer, have been carried out just in [11], while the other works concentrated principally on the studies of the most abundant cations. A complete mass spectrum of pyridazine is included in the NIST database [15] (originally from the Japan AIST/NIMC Database). The AEs of few selected cations have been obtained solely in [11]. The characteristic feature noticed in the fragmentation of pyridazine parent cation was loss of the $\mathrm{N}_{2}$ and $\mathrm{HCN}$ stable neutral molecules from the molecular ring. The mass spectra of pyridazine have been also explored using fast (keV) proton impact fragmentation [16] and charge exchange with low kinetic energy positive ions [17]. Fragmentation patterns in pyridazine have also been investigated by photoionization mass spectroscopy in the $13.8-23.0 \mathrm{eV}$ photon energy range. These photoionization measurements revealed, in general, the same cations as seen in the electron collision experiments, but the relative intensities of the cations were different [18]. For example, the $23.0 \mathrm{eV}$ mass spectrum shows the greatest intensity for the $52 \mathrm{amu}$ peak ascribed to a cationic fragment developed by the loss of $\mathrm{HCNH}$ or $\mathrm{N}_{2}$, whereas the parent cation $(m=80 \mathrm{amu})$ reached only $15 \%$ of the $52 \mathrm{amu}$ intensity [18]. Similar behavior of intensities of the mass peaks has been observed in electron-stimulated desorption of cations from submonolayer condensed pyridazine [19].
In particular in the present work, we have investigated the mass spectra of pyridazine and measured yields of the majority of the observed cations as a function of incident electron energy up to $140 \mathrm{eV}$. The AEs of most of the detected cations have also been determined. The observed mass peaks have been assigned and the possible fragmentation processes of the parent pyridazine cations are discussed. Moreover, the total cross section for electron impact ionization of pyridazine has been calculated, using the binary-encounter-Bethe (BEB) model for energies from the ionization threshold up to $4 \mathrm{keV}$. Furthermore, the absolute experimental total and partial ionization cross sections of pyridazine have been derived over the energy range from the respective ionization thresholds up to $140 \mathrm{eV}$. This was achieved by normalizing to the maximum of the calculated total ionization cross section, which has a value of $12.72 \times 10^{-20} \mathrm{~m}^{2}$. The preliminary results of the present work have been communicated in a conference abstract [20]. In these results, it was noticed that the mass spectrum shown at $60 \mathrm{eV}$ suffered from minor contaminations in the mass spectrometer from the earlier studied substances (tetrahydrofuran, pyridine). In addition, the $\mathrm{H}^{+}$and $\mathrm{H}_{2}^{+}$peaks were found not to be due to direct ionization of pyridazine.

\section{Experimental details}

The mass spectra of pyridazine and the cation yields as a function of incident electron energy were studied using an EPIC 300 (Hiden Analytical Ltd.) quadrupole mass spectrometer. The internal electron ionization stage of the spectrometer was used as the source of cations, which were focused onto the entrance to the mass filter. The transmission characteristics of the spectrometer system, ionization stage, mass filter and secondary electron multiplier, were established in our previous work [1], to be fairly independent of the cation mass in the range from about 10 to $120 \mathrm{amu}$. The mass resolution of the system, inferred from the measured spectra, was $\leq 0.9 \mathrm{amu}$. In the measurements, the electron beam current was constant and was maintained at a value from the range $5-20 \mu \mathrm{A}$. The energy spread of the electrons in the ionization stage was $0.6 \mathrm{eV}$ (FWHM) and was fairly independent of the electron energy considering small changes of the filament emission current. This value was derived from an ionization curve of argon that was measured near threshold. The electron energy was calibrated against the ionization threshold of argon $(15.76 \mathrm{eV})$ with an uncertainty of $\pm 0.04 \mathrm{eV}$. The pyridazine vapour was introduced into the spectrometer by effusion from a capillary that was positioned about $5 \mathrm{~mm}$ from the ionization region. The spectrometer was operated at pressures of $1-3 \times 10^{-6}$ mbar, whereas the background signal was recorded at $2-3 \times 10^{-7}$ mbar. This background was subsequently subtracted from the measured spectra. The cation yields measured as a function of incident electron energy were corrected for the energy variation of the electron beam current. The applied correction function was derived from comparison of the $\mathrm{Ar}^{+}$yield curve, measured in a mixture with pyridazine, with the $\mathrm{Ar}^{+}$ionization cross 
Table 1. Appearance energies (AEs) and the Wannier exponents $p$ together with their uncertainties obtained for cations of the pyridazine molecules.

\begin{tabular}{llll}
\hline$m(\mathrm{amu})$ & Present work & & Momigny et al. [11] \\
\hline & AE & $p$ & \\
81 & $8.55 \pm 0.15$ & $2.8 \pm 0.2$ & 9.77 \\
79 & $8.55 \pm 0.15$ & $2.9 \pm 0.2$ & \\
53 & $9.9 \pm 0.3$ & $1.8 \pm 0.3$ & 11.64 \\
52 & $11.05 \pm 0.15$ & $1.6 \pm 0.1$ & 13.84 \\
51 & $11.40 \pm 0.15$ & $2.6 \pm 0.2$ & 13.67 \\
50 & $12.8 \pm 0.4$ & $2.0 \pm 0.4$ & \\
49 & $12.7 \pm 0.3$ & $1.6 \pm 0.2,1.6 \pm 0.2$ & \\
38 & $16.6 \pm 0.4,25.0 \pm 0.3$ & $1.4 \pm 0.2,2.0 \pm 0.2$ & 14.94 \\
37 & $14.3 \pm 0.2,17.8 \pm 0.2$ & $2.0 \pm 0.3$ & \\
36 & $17.6 \pm 0.2$ & $2.2 \pm 0.2$ & \\
28 & $29.7 \pm 0.3$ & $1.6 \pm 0.2$ & \\
26 & $13.7 \pm 0.2$ & $2.3 \pm 0.2$ & \\
25 & $13.9 \pm 0.3$ & $1.8 \pm 0.2$ & \\
24 & $17.4 \pm 0.2$ & $1.6 \pm 0.2$ & \\
15 & $23.3 \pm 0.2$ & $1.8 \pm 0.1$ & \\
14 & $14.4 \pm 0.3$ & $1.6 \pm 0.1$ & \\
13 & $15.0 \pm 0.4$ & $2.2 \pm 0.2$ & \\
12 & $20.1 \pm 0.3$ & $2.0 \pm 0.2$ & \\
\hline
\end{tabular}

${ }^{a}$ Ionization energy [44].

${ }^{\mathrm{b}} \mathrm{AE}[45]$.

section [21]. The function appeared to change smoothly with energy, it decreased by $20 \%$ up to about $40 \mathrm{eV}$, then stayed approximately unchanged to increase by $10 \%$ above about $80 \mathrm{eV}$. The presented cation yield curves and the appearance potentials (see below) have been averaged over three to five independent measurements. The uncertainties in the shapes of the yield curves are $\pm 9 \%$ up to about $30 \mathrm{eV}$ and $\pm 4 \%$ in the region of $130 \mathrm{eV}$.

The AEs were obtained from the cation yield energy dependences measured above the AE thresholds, in short energy ranges not exceeding $5 \mathrm{eV}$. The yield functions were fitted with an exponential near-threshold cross-section function $\sigma(E)=c\left(E-E_{A}\right)^{p}$, where $E_{A}$ is the $\mathrm{AE}, p$ the Wannier exponent and $c$ the scaling factor. The $\sigma(E)$ function was convoluted with a Gaussian, which approximated the electron energy spread of $0.6 \mathrm{eV}$ (FWHM). This fitting procedure was suggested and used by Märk [22] and further refined by Matt et al. [23]. The AEs and exponents $p$ obtained from the fitting together with their uncertainties are listed in Table 1. More experimental details on the employed apparatus and data analysis may be found in our previous articles $[1,24]$.

\section{Theoretical calculations}

Electron impact total ionization cross-section has been calculated within the BEB formalism [25] for energies from the ionization threshold up to $4 \mathrm{keV}$. According to the BEB model $[25,26]$ the ionization cross section per molecular orbital is given by the following formula

$$
\sigma^{B E B}=\frac{S}{t+u+1}\left[\frac{\ln t}{2}\left(1-\frac{1}{t^{2}}\right)+1-\frac{1}{t}-\frac{\ln t}{t+1}\right],
$$

where $u=U / B, \quad t=T / B, \quad S=4 \pi a_{0}^{2} N R^{2} / B^{2}, \quad a_{0}=$ $0.5292 \AA, R=13.61 \mathrm{eV}, U$ is the kinetic energy of an electron on the orbital, $B$ the electron binding energy, $N$ the orbital occupation number and $T$ is the energy of the incident electrons. The total cross section $\sigma^{i o n}$ for electron ionization is obtained from the sum of ionization cross sections for molecular orbitals

$$
\sigma^{i o n}=\sum_{i=1}^{n_{\mathrm{MO}}} \sigma_{i}^{B E B},
$$

where $n_{\mathrm{MO}}$ is the number of included molecular orbitals. All quantities in equation (1) have well defined physical meanings and in computations can be evaluated within quantum chemical methods using molecular structure ab initio codes. The accuracy of the final ionization cross section depends on the quality of the calculated ionization potentials and kinetic orbital energies. While the above theoretical approach remains as a model, the advantage of the method is that it does not contain any adjustable free parameters. Usually, the BEB ionization cross sections are in accord, within $15 \%$, with the absolute measured quantities [27-29].

In this work the electron binding energy $B$, kinetic energy of the orbital $U$ and the orbital occupation number $N$ have been calculated for the ground state of the geometrically optimized pyridazine molecule applying the Hartree-Fock (RHF) method using the GAUSSIAN code [30] and 6-31G basis set. Because the calculated ionization energies in this approach usually exceed (even by more than $1 \mathrm{eV}$ ) the measured values, we have also performed outer valence Green function calculations of correlated electron affinities and ionization potentials using the same GAUSSIAN code and 6-31G basis set [31-34]. The 
equilibrium geometry of the pyridazine molecule obtained within $\mathrm{C}_{2 \mathrm{v}}$ symmetry is in a very good agreement with the earlier theoretical results. For example, the obtained bond lengths and angles, $r \mathrm{~N}(1) \mathrm{N}(2)=1.3240 \AA, r \mathrm{~N}(2) \mathrm{C}(3)=$ $1.3252 \AA, r \mathrm{C}(3) \mathrm{C}(4)=1.3921 \AA, r \mathrm{C}(4) \mathrm{H}(8)=1.0711 \AA$, $\angle \mathrm{C}(6) \mathrm{N}(1) \mathrm{N}(2)=120.112^{\circ} \quad$ and $\quad \angle \mathrm{N}(1) \mathrm{N}(2) \mathrm{C}(3)=$ $122.564^{\circ}$ (see Fig. 1 for labelling of atoms) are in excellent agreement with the RHF calculations [35] and also in quite satisfactory agreement with the DFT calculations, which used the aug-CC-pVDZ basis set [36]. The obtained structural parameters are also consistent with the results derived from electron diffraction [37] and electron diffraction, microwave and liquid-crystal NMR spectra [38]. The electric dipole moment of pyridazine calculated using the $6-31 \mathrm{G}^{*}$ basis set, $\mu_{D}=4.42 \mathrm{D}$, agrees very well with the earlier self-consistent field [39], configuration interaction [39] and RHF [35] computations. In the electronic structure calculations using the $6-31 \mathrm{G}$ basis set and OVGF method, the following ionization potentials were obtained: $8 b_{2}-8.473 \mathrm{eV}, 1_{a 2}-10.482 \mathrm{eV}, 2 b_{1}-10.808 \mathrm{eV}$, $10 a_{1}-10.922 \mathrm{eV}, 1 b_{1}-14.346 \mathrm{eV}, 9 a_{1}-14.154 \mathrm{eV}, 7 b_{2}-$ $14.786 \mathrm{eV}, 6 b_{2}-16.532 \mathrm{eV}, 8 a_{1}-17.069 \mathrm{eV}$, and $7 a_{1}-17.969 \mathrm{eV}$. These results are consistent with the earlier calculations using methods, in which electron correlation effects are included, the OVGF method with cc-pVDZ basis set [40], CAS-SCF method and the NEVPT2 method with cc-pVTZ basis set [41]. In general, they are also comparable with the experimental results $[2,17,42]$ (see below).

\section{Results and discussion}

The ionization of molecules by electron collisions in the energy region up to about $1 \mathrm{eV}$ above the first ionization threshold creates, in general, stable parent cations, which have a vacancy in their highest occupied molecular orbital (HOMO). At higher electron impact energy, electrons from valence orbitals of the cations, with higher binding energies, may be removed. This destabilizes the cations and may initiate dissociation (dissociative ionization), dipolar dissociation and also Coulomb explosion. In pyridazine the valance orbitals $\left(\mathrm{C}_{2 \mathrm{v}}\right.$ symmetry $)$, which may be here considered are: $8 \mathrm{~b}_{2}\left(\mathrm{n}_{\mathrm{N}_{-}}\right)(9.27 \mathrm{eV}), 1 \mathrm{a}_{2}\left(\pi_{3}\right)$ $(10.61 \mathrm{eV}), 2 \mathrm{~b}_{1}\left(\pi_{2}\right)(11.2 \mathrm{eV}), 10 \mathrm{a}_{1}\left(\mathrm{n}_{\mathrm{N}+}\right)(11.3 \mathrm{eV}), 1 \mathrm{~b}_{1}$ $\left(\pi_{1}\right)(13.97 \mathrm{eV}), 9 \mathrm{a}_{1}(14.27 \mathrm{eV})$ and $7 \mathrm{~b}_{2}(14.66 \mathrm{eV})$. The values in parentheses are the vertical ionization energies determined from the He I UPS spectra by Kishimoto and Ohno [2]. The $8 \mathrm{~b}_{2}$ and $10 \mathrm{a}_{1}$ orbitals are the $\left(\mathrm{n}_{\mathrm{N}}\right)$ nitrogen lone-pair orbitals.

\subsection{Cation mass spectrum of pyridazine}

The cation mass spectrum of pyridazine, recorded at a fixed electron energy of $100 \mathrm{eV}$, is presented in Figure 2. This figure also displays the assignments of the mass peaks in the spectrum, while Table 2 lists the abundances of the cations deduced from the spectrum. The pyridazine parent $\mathrm{C}_{4} \mathrm{H}_{4} \mathrm{~N}_{2}^{+}$cation, at $m=80 \mathrm{amu}$, shows the highest intensity in the spectrum. The mass peaks in the spectrum occur in groups, which are well separated on the

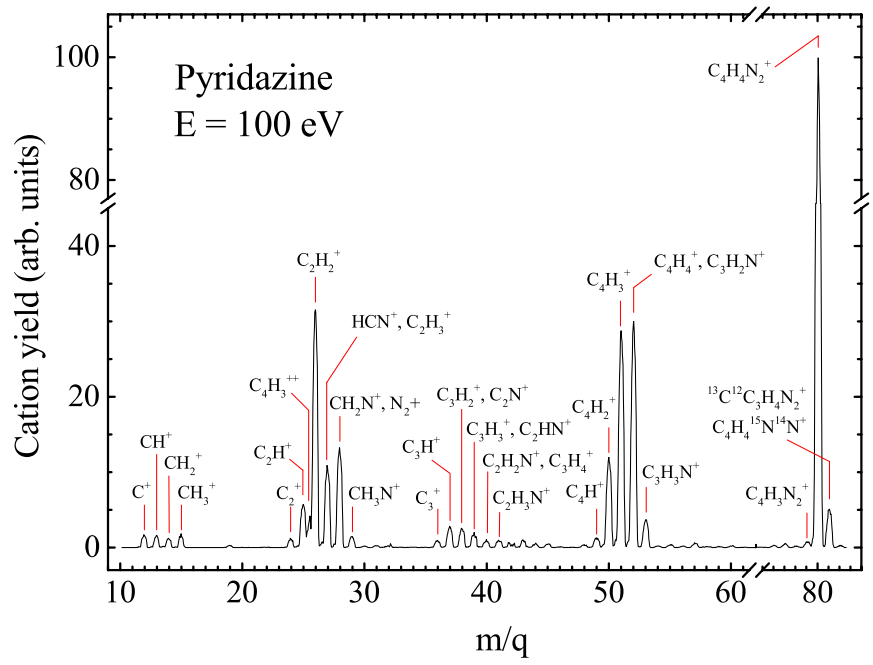

Fig. 2. The cation mass spectrum of pyridazine recorded at an electron energy of $100 \mathrm{eV}$.

mass scale. These groups may be identified by the number of atoms, carbon and nitrogen, incorporated in the cations from the molecular ring. This grouping of peaks is typical for hydrocarbon ionization mass spectra (see e.g. $[1,24])$. In the first group, in the $12-15$ amu mass range, the cations contain one (carbon) atom, while in the fourth group, in the 48-53 amu range, four (carbon or carbon and nitrogen) atoms. The present spectrum is in general agreement with that presented in the NIST database [15].

The AEs obtained for most of the detected cations are listed in Table 1, together with their estimated uncertainties, where are compared with the other available, although very scarce, results. The table also displays Wannier exponents $p$ deduced from the cation yield curves measured over short ranges above thresholds. The Wannier exponents vary between 1.4 and 2.9. The values of $p$ between 1.2 and 1.4 mark processes equivalent to single channel of ionization in the atomic cases (e.g. helium, argon). Higher exponents ( $\gtrsim 2)$, not having direct physical meaning, may indicate contributions from several fragmentation channels (including vibrational) for a given cation mass, what was suggested by Fiegele et al. [43], when extending the Wannier law to the ionization of the polyatomic molecules. In the polyatomic cases the AEs and the Wannier exponent $p$ can be extracted from the experimental ionization curves, however it has to be noted that these parameters, for a given mass, should be considered as values averaged over the contributing fragmentation channels. The uncertainties listed in Table 1 for $\mathrm{AE}$ and $p$ reflect mainly the experimental accuracy of their determination. Figure 3 displays the above-threshold yield curves for selected pyridazine cations and illustrates the high quality of the fitting that is achieved by using exponential functions.

\subsubsection{Cations: $m=77-82$ amu}

The AE of the parent cation $(m=80 \mathrm{amu})$ determined in the present work is $8.55 \pm 0.15 \mathrm{eV}$ (Tab. 1) and is about $1.2 \mathrm{eV}$ lower than the only earlier measurement by 
Table 2. Assignments, neutral fragments and relative abundances of the pyridazine cations measured at an electron energy of $100 \mathrm{eV}$. Percentage uncertainties are given for the abundances.

\begin{tabular}{llll}
\hline$m(\mathrm{amu})$ & $\mathrm{Cation}$ & Neutral fragment & Relative abundance \\
\hline 81 & ${ }^{13} \mathrm{C}^{12} \mathrm{C}_{3} \mathrm{H}_{4} \mathrm{~N}_{2}^{+}, \mathrm{C}_{4} \mathrm{H}_{4}^{15} \mathrm{~N}^{14} \mathrm{~N}^{+}$ & - & $5.08 \pm 3.5 \%$ \\
80 & $\mathrm{C}_{4} \mathrm{H}_{4} \mathrm{~N}_{2}^{+}$ & - & 100 \\
79 & $\mathrm{C}_{4} \mathrm{H}_{3} \mathrm{~N}_{2}^{+}$ & $\mathrm{H}$ & $0.78 \pm 20 \%$ \\
53 & $\mathrm{C}_{3} \mathrm{H}_{3} \mathrm{~N}^{+}$ & $\mathrm{HCN}$ & $3.71 \pm 8 \%$ \\
52 & $\mathrm{C}_{4} \mathrm{H}_{4}^{+}, \mathrm{C}_{3} \mathrm{H}_{2} \mathrm{~N}^{+}$ & $\mathrm{N}_{2}, \mathrm{HCN}+\mathrm{H}$ & $30.0 \pm 10 \%$ \\
51 & $\mathrm{C}_{4} \mathrm{H}_{3}^{+}$ & $\mathrm{N}_{2}+\mathrm{H}$ & $28.7 \pm 4.5 \%$ \\
50 & $\mathrm{C}_{4} \mathrm{H}_{2}^{+}$ & $\mathrm{N}_{2}+\mathrm{H}+\mathrm{H}\left(\mathrm{N}_{2}+\mathrm{H}_{2}\right)$ & $11.9 \pm 10 \%$ \\
49 & $\mathrm{C}_{4} \mathrm{H}^{+}$ & $\mathrm{N}_{2}+\mathrm{H}+\mathrm{H}+\mathrm{H}$ & $1.22 \pm 14 \%$ \\
40 & $\mathrm{C}_{2} \mathrm{H}_{2} \mathrm{~N}^{+}, \mathrm{C}_{3} \mathrm{H}_{4}^{+}$ & $\mathrm{C}_{2} \mathrm{H}_{2} \mathrm{~N}, \mathrm{CN}_{2}$ & $0.88 \pm 10 \%$ \\
39 & $\mathrm{C}_{2} \mathrm{HN}^{+}, \mathrm{C}_{3} \mathrm{H}_{3}^{+}$ & $\mathrm{C}_{2} \mathrm{H}_{3} \mathrm{~N}, \mathrm{CHN}_{2}$ & 1.74 \\
38 & $\mathrm{CH}_{3} \mathrm{H}_{2}^{+}, \mathrm{C}_{2} \mathrm{~N}^{+}$ & & $2.49 \pm 6.5 \%$ \\
37 & $\mathrm{C}_{3} \mathrm{H}^{+}$ & & $2.81 \pm 6 \%$ \\
36 & $\mathrm{C}_{3}^{+}$ & & $0.86 \pm 6.5 \%$ \\
29 & $\mathrm{CH}_{3} \mathrm{~N}^{+}$ & & 1.42 \\
28 & $\mathrm{CH}_{2} \mathrm{~N}^{+}, \mathrm{N}_{2}^{+}, \mathrm{C}_{2} \mathrm{H}_{4}^{+}$ & $\mathrm{C}_{4} \mathrm{H}_{4}$ & $13.2 \pm 20 \%$ \\
27 & $\mathrm{HCN}^{+}, \mathrm{C}_{2} \mathrm{H}_{3}^{+}$ & $\mathrm{C}_{3} \mathrm{H}_{3} \mathrm{~N}$ & $10.4 \pm 12 \%$ \\
26 & $\mathrm{C}_{2} \mathrm{H}_{2} \mathrm{~N}_{2}(2 \mathrm{HCN})$ & $31.5 \pm 15 \%$ \\
25 & $\mathrm{C}_{2} \mathrm{H}_{2}^{+}, \mathrm{CN}^{+}$, & $\mathrm{HCN}^{+}+\mathrm{HCN}+\mathrm{H}$ & $5.73 \pm 14 \%$ \\
24 & $\mathrm{C}_{2} \mathrm{H}^{+}$ & $\mathrm{HCN}+\mathrm{HCN}+\mathrm{H}+\mathrm{H}$ & $1.03 \pm 10 \%$ \\
15 & $\mathrm{C}_{2}^{+}$ & & 1.52 \\
14 & $\mathrm{CH}_{3}^{+}$ & & 1.13 \\
13 & $\mathrm{CH}_{2}^{+}$ & & $1.63 \pm 6.5 \%$ \\
12 & $\mathrm{CH}^{+}$ & & $1.63 \pm 6.5 \%$
\end{tabular}

Momigny et al. [11]. It is in accord with the adiabatic ionization energy of $8.7088 \mathrm{eV}$ obtained by Choi et al. [36] for the $8 \mathrm{~b}_{2}\left(\mathrm{n}_{\mathrm{N}-}\right)$ photoelectron band by VUV massanalyzed threshold ionization spectroscopy (see also [17]). The present measurement is also in accord with the first ionization energy of $8.71 \mathrm{eV}$, determined by Yencha et al. [44] from the recorded photoionization yield curve. It is interesting to note that the onsets of the $8 \mathrm{~b}_{2}\left(\mathrm{n}_{\mathrm{N}-}\right)$ vibronic band read out from the photoelectron spectra shown in $[2,42]$ lie between 8.55 and $8.64 \mathrm{eV}$. This may point to the possible contribution of hot bands in the measurements.

The cation peaks appearing in the mass spectrum in the range 77-79 amu are of low intensity but they may be rather firmly ascribed to dehydrogenated parent cations. The AE of the $\mathrm{C}_{4} \mathrm{H}_{3} \mathrm{~N}_{2}^{+}$cation $(m=79 \mathrm{amu})$, which is formed by abstraction of a single $\mathrm{H}$, is $9.9 \mathrm{eV}$. Thus, the $\mathrm{C}_{4} \mathrm{H}_{4} \mathrm{~N}_{2}^{+}$cation detaching $\mathrm{H}$ remains in the $8 \mathrm{~b}_{2}^{-1}$ ground state and may be highly vibrationally excited, as the $\mathrm{AE}$ is about $1.2 \mathrm{eV}$ above the $8 \mathrm{~b}_{2}$ adiabatic ionization energy. It has been argued $[36,42]$ that vacancy in the $8 b_{2}\left(n_{N-}\right)$ lone-pair orbital, which is strongly mixed with the $\sigma(\mathrm{C}-\mathrm{H})$ orbital, produces significant changes in the pyridazine ring structure. The $\mathrm{C}_{4} \mathrm{H}_{2} \mathrm{~N}_{2}^{+}$cation $(m=78 \mathrm{amu})$ is formed by removal of $\mathrm{H}_{2}$ (or two $\mathrm{H}$ atoms), while $\mathrm{C}_{4} \mathrm{HN}_{2}^{+}(m=$ $77 \mathrm{amu}$ ) involves the loss of three $\mathrm{H}$ atoms by the parent cation.

The cation peaks at 81 and 82 amu in the mass spectrum (Fig. 2) correlate with the pyridazine isotopes built from naturally occurring ${ }^{13} \mathrm{C},{ }^{15} \mathrm{~N}$ and ${ }^{2} \mathrm{H}$ (deuterium). The 81 amu peak contains predominantly the ${ }^{13} \mathrm{C}^{12} \mathrm{C}_{3} \mathrm{H}_{4} \mathrm{~N}_{2}^{+}$and $\mathrm{C}_{4} \mathrm{H}_{4}{ }^{15} \mathrm{~N}^{14} \mathrm{~N}^{+}$isotopes, which have calculated relative abundancies of 4.33 and 0.72 , respectively. The measured intensity of the $81 \mathrm{amu}$ peak (see Tab. 2) is in accord with the calculated total abundancy of 5.11. The 82 amu peak may comprise contributions of six molecular isotopes, although the calculated relative abundances indicate the predominance of ${ }^{13} \mathrm{C}_{2}{ }^{12} \mathrm{C}_{2} \mathrm{H}_{4} \mathrm{~N}_{2}^{+} \quad(0.145)$ and ${ }^{13} \mathrm{C}^{12} \mathrm{C}_{3} \mathrm{H}_{4}{ }^{15} \mathrm{~N}^{14} \mathrm{~N}^{+}$(0.033) isotopes. The $\mathrm{AE}$ measured for the $81 \mathrm{amu}$ mass isotope is equal to that of the parent cation $(8.55 \mathrm{eV})$.

\subsubsection{Cations: $m=49-53 \mathrm{amu}$}

The masses of the pyridazine cations recorded in this region of the mass spectrum denote losses of neutral HCN $(m=27 \mathrm{amu})$ or $\mathrm{N}_{2}(m=28 \mathrm{amu})$ stable molecules by the parent cations, which may be further accompanied by abstraction of $\mathrm{H}$ atoms. The 53 and 52 amu peaks match the $\mathrm{C}_{3} \mathrm{H}_{3} \mathrm{~N}^{+}$and $\mathrm{C}_{4} \mathrm{H}_{4}^{+}$cations formed by the loss of a single $\mathrm{HCN}$ or $\mathrm{N}_{2}[13,45]$ molecules, respectively. However, in the high resolution measurements Benn et al. [12] revealed that the 52 amu peak also contains a contribution $(26.5 \%$ at $70 \mathrm{eV})$ from the $\mathrm{C}_{3} \mathrm{H}_{2} \mathrm{~N}^{+}$cations. They are formed through the loss of a $\mathrm{H}$ atom by $\mathrm{C}_{3} \mathrm{H}_{3} \mathrm{~N}^{+}$, $\mathrm{C}_{3} \mathrm{H}_{3} \mathrm{~N}^{+} \rightarrow \mathrm{C}_{3} \mathrm{H}_{2} \mathrm{~N}^{+}+\mathrm{H}$, as confirmed by observation of the corresponding metastable peaks in the mass spectrum [11]. The AE determined for the 52 amu cation is $11.40 \mathrm{eV}$, in good agreement with the value of $11.64 \mathrm{eV}$ obtained by Momigny et al. [11]. The present value of $\mathrm{AE}$ indicates that in the above-threshold energy region the $2 \mathrm{~b}_{1}^{-1}$ and $10 \mathrm{a}_{1}^{-1}$ cationic states of pyridazine must be initially populated. Buff and Dannacher [45], by applying a variable residence time threshold photoelectron-photoion coincidence spectroscopy, investigated fragmentation of the pyridazine parent cation, $\mathrm{C}_{4} \mathrm{H}_{4} \mathrm{~N}_{2}^{+} \rightarrow \mathrm{C}_{4} \mathrm{H}_{4}^{+}+\mathrm{N}_{2}$. 

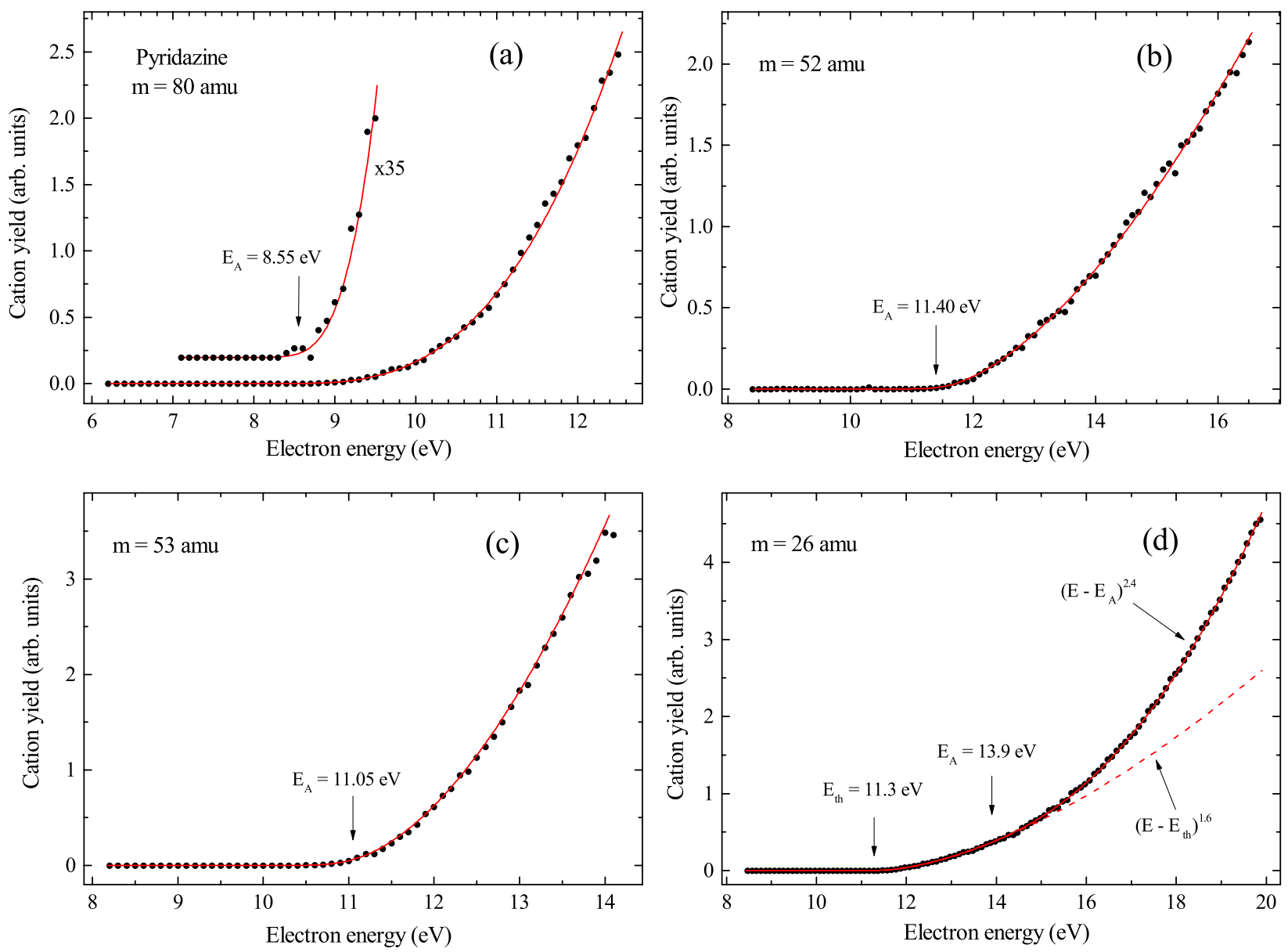

Fig. 3. The yield curves for cations of, (a) $m=80 \mathrm{amu}$, (b) $m=52 \mathrm{amu}$, (c) $m=53 \mathrm{amu}$ and (d) $m=26$ amu, of the pyridazine molecules measured in the near-threshold regions. The solid lines show exponential curves fitted to the experimental results. The appearance energies $E_{A}$ and the threshold energy $E_{t h}$ are indicated by arrows. The exponential functions shown in (d) were used in the fitting.

They deduced AE of $11.32 \mathrm{eV}$ for the above process, which is well supported by the present result of $11.40 \mathrm{eV}$. Their analyses of the obtained results imply that the fragmentation begins with a rate determining rupture of the pyridazine ring at one of the two $\mathrm{C}-\mathrm{N}$ bonds followed by elimination of the terminal $\mathrm{N}_{2}$ from the chain parent cation and that, more importantly, the fragmentation occurs on the ground state hypersurface of the cation. This further imply that in the above-threshold energy region the initial population of the $2 \mathrm{~b}_{1}^{-1}$ and $10 \mathrm{a}_{1}^{-1}$ cationic states of pyridazine has to be followed by rapid internal conversion to the cationic ground state. Both, $2 b_{1}^{-1}$ and $10 \mathrm{a}_{1}^{-1}$, cationic states of pyridazine are also involved in the process $\mathrm{C}_{4} \mathrm{H}_{4} \mathrm{~N}_{2}^{+} \rightarrow \mathrm{C}_{3} \mathrm{H}_{3} \mathrm{~N}^{+}+\mathrm{HCN}$, as may be implied from the measured $\mathrm{AE}$ of $11.05 \mathrm{eV}$ (Tab. 1). Ejection of the $2 b_{1}$ or $10 a_{1}$ electrons in ionization weakens the $\mathrm{N}-\mathrm{N}$ bond (see schematic diagrams of the molecular orbitals of pyridazine [2]) prompting the opening of the molecular ring at the $\mathrm{N}-\mathrm{N}$ bond and the elimination of one of the two terminal HCNs.

The mass peaks at 51, 50 and $49 \mathrm{amu}$ are assigned primarily to the $\mathrm{C}_{4} \mathrm{H}_{3}^{+}, \mathrm{C}_{4} \mathrm{H}_{2}^{+}$and $\mathrm{C}_{4} \mathrm{H}^{+}$cations, respectively. We suggest that these three cations originate from the sequential loss of hydrogen atoms in a chain of processes commencing at $\mathrm{C}_{4} \mathrm{H}_{4}^{+}$:

$$
\begin{gathered}
\mathrm{C}_{4} \mathrm{H}_{4}^{+} \rightarrow \mathrm{C}_{4} \mathrm{H}_{3}^{+}+\mathrm{H}, \\
\mathrm{C}_{4} \mathrm{H}_{3}^{+} \rightarrow \mathrm{C}_{4} \mathrm{H}_{2}^{+}+\mathrm{H} \\
\text { (or } \mathrm{C}_{4} \mathrm{H}_{4}^{+} \rightarrow \mathrm{C}_{4} \mathrm{H}_{2}^{+}+\mathrm{H}_{2}, \mathrm{C}_{4} \mathrm{H}_{4}^{+} \rightarrow \mathrm{C}_{4} \mathrm{H}_{2}^{+}+\mathrm{H}+\mathrm{H} \text { ) } \\
\text { nd } \quad \mathrm{C}_{4} \mathrm{H}_{2}^{+} \rightarrow \mathrm{C}_{4} \mathrm{H}^{+}+\mathrm{H} \text {. }
\end{gathered}
$$

and

Such step by step decomposition of cations has been found in pyridine by observing the metastable peaks in the mass spectrum [11]. The measured AEs of the $\mathrm{C}_{4} \mathrm{H}_{3}^{+}$ and $\mathrm{C}_{4} \mathrm{H}_{2}^{+}$cations, 12.8 and $12.7 \mathrm{eV}$, respectively, point towards concurrent participation of the $2 \mathrm{~b}_{1}^{-1}$ and $10 \mathrm{a}_{1}^{-1}$ excited (including vibrationally) states in the fragmentation into those species. The AEs are about $1 \mathrm{eV}$ lower than those determined previously by Momigny et al. [11]. The $\mathrm{C}_{4} \mathrm{H}^{+}$cations display two appearance thresholds at the higher energies of 16.6 and $25.0 \mathrm{eV}$. It has to be noted that the 51 and $50 \mathrm{amu}$ peaks in the mass spectrum may 
contain contributions from $\mathrm{C}_{3} \mathrm{HN}^{+}$and $\mathrm{C}_{3} \mathrm{~N}^{+}$cations, respectively, that are produced by detachment of $\mathrm{HCN}$ from the parent cation and sequential losses of the hydrogen atoms. For example, the $\mathrm{C}_{3} \mathrm{HN}^{+}$cation is produced in the dissociation $\mathrm{C}_{3} \mathrm{H}_{2} \mathrm{~N}^{+} \rightarrow \mathrm{C}_{3} \mathrm{HN}^{+}+\mathrm{H}$ [11]. These contributions, however, may be expected to be low, as may be judged from the contribution of $\mathrm{C}_{3} \mathrm{H}_{2} \mathrm{~N}^{+}$into the $52 \mathrm{amu}$ peak. By comparison, fragmentation of pyrimidine into 50-53 amu cations results solely in the loss of the HCN moiety $[1,11]$. This difference in the dominating decomposition processes by loss of $\mathrm{N}_{2}$ and $\mathrm{HCN}$ between pyridazine and pyrimidine, respectively, stems from the different relative positions of the two nitrogen atoms in both molecular rings (see Fig. 1).

\subsubsection{Cations: $m=24-29 \mathrm{amu}$}

The 26 amu peak, which has the greatest intensity in this mass region, is ascribed to the $\mathrm{C}_{2} \mathrm{H}_{2}^{+}$cations produced by direct cleavages of the two bonds, $\mathrm{C}(3)-\mathrm{C}(4)$ and $\mathrm{C}(5)-\mathrm{C}(6)$ (Fig. 1), in the pyridazine parent cation. Concurrently, in the fragmentation process, the neutral $\mathrm{C}_{2} \mathrm{H}_{2} \mathrm{~N}_{2}$ moieties may develop, $\mathrm{C}_{4} \mathrm{H}_{4} \mathrm{~N}_{2}^{+} \rightarrow \mathrm{C}_{2} \mathrm{H}_{2}^{+}+$ $\mathrm{C}_{2} \mathrm{H}_{2} \mathrm{~N}_{2}$. However, the higher value of the $\mathrm{C}_{2} \mathrm{H}_{2}^{+} \mathrm{AE}$ of $13.9 \mathrm{eV}$ (see Tab. 2), which comes close to that of pyrimidine $(14.20 \mathrm{eV}[1])$ may instead mark the loss of two neutral HCN fragments by the parent cations of both molecules. The 26 amu peak in pyridazine may also contain contribution from the $\mathrm{CN}^{+}$cyano radical, although of small abundancy ( 0.25$)$ as seen by Momigny et al. [11]. It is of note, that the $\mathrm{C}_{2} \mathrm{H}_{2}^{+}$cations were also detected below $13.9 \mathrm{eV}$, in the energy region from a threshold $E_{t h}=11.3 \pm 0.2 \mathrm{eV}$. Figure 3d illustrates how the threshold energy $E_{t h}$ and $\mathrm{AE}$ of $\mathrm{C}_{2} \mathrm{H}_{2}^{+}$have been determined by fitting the $\mathrm{C}_{2} \mathrm{H}_{2}^{+}$yield energy dependence by two separate exponential functions, $\left(E-E_{t h}\right)^{1.6}$ and $\left(E-E_{A}\right)^{2.4}$. The $E_{t h}$ energy coincides, within its uncertainty, with the ionization energy $11.41 \pm 0.01 \mathrm{eV}[46]$ of the $\mathrm{C}_{2} \mathrm{H}_{2}$ neutral molecule. This coincidence of energies suggests that below $13.9 \mathrm{eV}$, the $\mathrm{C}_{2} \mathrm{H}_{2}^{+}$cations originate from direct ionization of $\mathrm{C}_{2} \mathrm{H}_{2}$ molecules. Such molecules may be produced by thermionic decomposition or electron impact dissociation of pyridazine in the filament area of the ionization stage of the spectrometer. The signal due to this direct ionization of the $\mathrm{C}_{2} \mathrm{H}_{2}$ varied approximately linearly with the incident electron current, thus supporting the conclusion that $\mathrm{C}_{2} \mathrm{H}_{2}$ molecules were produced by thermionic decomposition. This contribution to the $26 \mathrm{amu}$ mass peak at $100 \mathrm{eV}$ is estimated, using the known ionization cross section of acetylene molecules [47], to be at the level of $20 \%$. It has been subtracted to give the spectrum shown in Figure 2 and accordingly has been removed from the energy dependence of the 26 amu peak intensity shown in Figure 4b. Interestingly, Li et al. [48] in their recent mass spectrometry studies of $\mathrm{N}$-methylformamide cationic fragmentation, using a quadrupole mass spectrometer, have detected $\mathrm{CH}_{3}$ neutral radicals below the threshold for producing $\mathrm{CH}_{3}^{+}$from the ionizing fragmentation. They attributed the existence of $\mathrm{CH}_{3}$ generated in that energy region to dissociation of the target molecules by electron collisions.

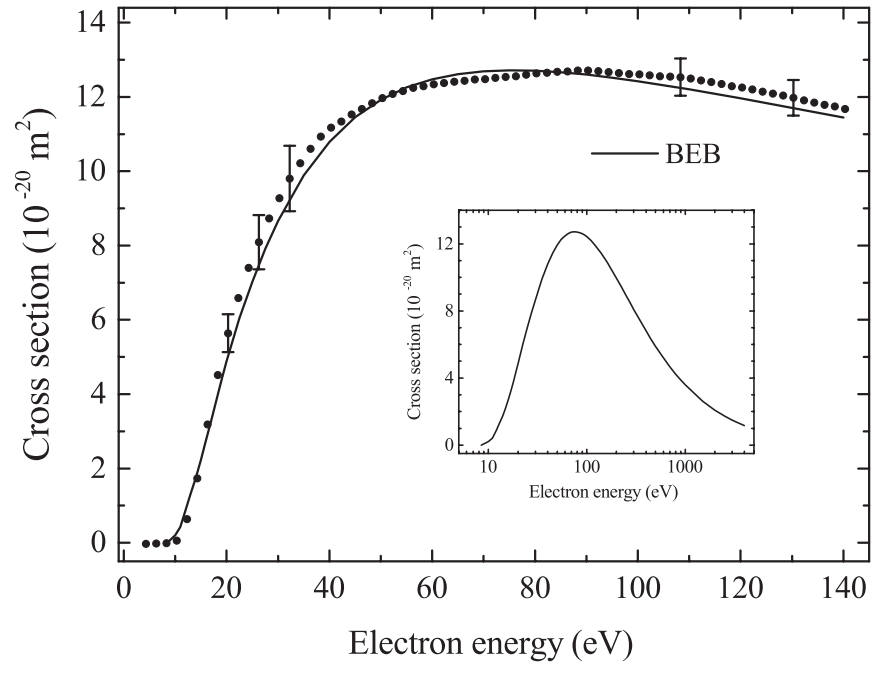

Fig. 4. The total ionization cross sections obtained in the measurements and in the binary-encounter-Bethe (BEB) calculations. The error bars show uncertainties in the shape of the energy dependence of the cross section. The total experimental yield was normalized to the computed cross section of $12.72 \times 10^{-20} \mathrm{~m}^{2}$ at $88 \mathrm{eV}$. Inset shows the BEB cross section calculated in the electron energy range to $4 \mathrm{keV}$.

The 25 and 24 amu peaks in the mass spectrum of pyridazine are ascribed to the $\mathrm{C}_{2} \mathrm{H}^{+}$and $\mathrm{C}_{2}^{+}$cations created by loss of $\mathrm{H}$ and $\mathrm{H}_{2}$ by the $\mathrm{C}_{2} \mathrm{H}_{2}^{+}$cations: $\mathrm{C}_{2} \mathrm{H}_{2}^{+} \rightarrow \mathrm{C}_{2} \mathrm{H}^{+}+\mathrm{H}$ and $\mathrm{C}_{2} \mathrm{H}_{2}^{+} \rightarrow \mathrm{C}_{2}^{+}+\mathrm{H}_{2}$ or $\mathrm{C}_{2} \mathrm{H}_{2}^{+} \rightarrow \mathrm{C}_{2}^{+}$ $+\mathrm{H}+\mathrm{H}$ (or $\mathrm{C}_{2} \mathrm{H}^{+} \rightarrow \mathrm{C}_{2}^{+}+\mathrm{H}$ ), respectively. A strong decrease in their intensities with respect to that of the $\mathrm{C}_{2} \mathrm{H}_{2}^{+}$peak further supports these assignments. A higher value of the $\mathrm{C}_{2} \mathrm{H}^{+} \mathrm{AE}$ of $17.4 \mathrm{eV}$ suggests a more complex fragmentation pathway in this cationic channel. It is of note, that we do not see a second fragmentation process at higher energy, as was the case in pyrimidine [1]. Identically, a single AE threshold at $23.3 \mathrm{eV}$ is seen for the 24 amu cations. Between the 25 and 26 amu peaks, at a $\mathrm{m} / q$ of $25.5 \mathrm{amu}$, a low intensity peak (abundancy 4.2 ) is recorded in the mass spectrum. This gives evidence of the formation of $\mathrm{C}_{4} \mathrm{H}_{3}^{++}$dications of mass $51 \mathrm{amu}$.

The 27 amu peak in the mass spectrum contains contributions from two cations, $\mathrm{HCN}^{+}$and $\mathrm{C}_{2} \mathrm{H}_{3}^{+}$. Momigny et al. [11] found their abundances to be in the ratio of about $2: 1$ at $50 \mathrm{eV}$. The complementary neutral fragment in the dissociation of the parent cation into $\mathrm{HCN}^{+}$is $\mathrm{C}_{3} \mathrm{H}_{3} \mathrm{~N} ; \mathrm{C}_{4} \mathrm{H}_{4} \mathrm{~N}_{2}^{+} \rightarrow \mathrm{HCN}^{+}+\mathrm{C}_{3} \mathrm{H}_{3} \mathrm{~N}$. It is worth noting, that the $\mathrm{C}_{3} \mathrm{H}_{3} \mathrm{~N}^{+}(53 \mathrm{amu})$ cations are generated in an analogous fragment at ion pathway, $\mathrm{C}_{4} \mathrm{H}_{4} \mathrm{~N}_{2}^{+} \rightarrow \mathrm{HCN}+\mathrm{C}_{3} \mathrm{H}_{3} \mathrm{~N}^{+}$, but occur with a different position of the positive charge. The $28 \mathrm{amu}$ peak has been assigned by Momigny et al. [11] primarily to $\mathrm{CH}_{2} \mathrm{~N}^{+}$and $\mathrm{N}_{2}^{+}$, with abundances in the ratio of about $3: 1$ at $50 \mathrm{eV}$. The $\mathrm{C}_{2} \mathrm{H}_{4}^{+}$cations make a minor contribution of about $5 \%$ to the peak. This assignment of the $28 \mathrm{amu}$ cations has been further supported by Vall-Ilosera et al. [18] in photoionization mass spectrometry of pyridazine. It has been argued, that the $\mathrm{CH}_{2} \mathrm{~N}^{+}$cation may originate from $\mathrm{HCN}^{+}$detachment from the parent cation, together with 
Table 3. Experimental total cross section for ionization of the pyridazine molecules by electron impact.

\begin{tabular}{llll}
\hline$E(\mathrm{eV})$ & $\times 10^{-20} \mathrm{~m}^{2}$ & $E(\mathrm{eV})$ & $\times 10^{-20} \mathrm{~m}^{2}$ \\
\hline 10 & 0.05 & 50 & 11.95 \\
12 & 0.56 & 55 & 12.19 \\
14 & 1.57 & 60 & 12.34 \\
16 & 2.97 & 65 & 12.42 \\
18 & 4.32 & 70 & 12.48 \\
20 & 5.47 & 80 & 12.63 \\
22 & 6.45 & 85 & 12.69 \\
24 & 7.28 & 90 & 12.71 \\
26 & 7.99 & 95 & 12.66 \\
28 & 8.64 & 100 & 12.61 \\
30 & 9.20 & 110 & 12.56 \\
32 & 9.72 & 115 & 12.51 \\
34 & 10.15 & 120 & 12.39 \\
36 & 10.55 & 125 & 12.26 \\
38 & 10.88 & 135 & 11.99 \\
40 & 11.14 & 140 & 11.83 \\
42 & 11.32 & & \\
46 & 11.50 & 11.66 & 1.69
\end{tabular}

the addition of a $\mathrm{H}$ atom via its migration from the neighbouring $\mathrm{C}$ atom [18]. In pyrimidine, the 28 amu peak consists primarily of $\mathrm{CH}_{2} \mathrm{~N}^{+}$cations [11], as $\mathrm{N}_{2}^{+}$are less likely to form because of $\mathrm{C}-\mathrm{H}$ between the positions of the nitrogen atoms in the ring. The 29 amu peak in the mass spectrum has been ascribed to $\mathrm{CH}_{3} \mathrm{~N}^{+}[11]$. When the 24$29 \mathrm{amu}$ region of the mass spectrum of pyridazine (Fig. 2) is compared with the same region in the mass spectrum of pyrimidine a very close similarity in the shape and relative intensities of the mass peaks is clearly noticed; see Figure 3 of Linert et al. [1]. Thus, it seems that the relative positions of both nitrogen atoms in the ring are not decisive in producing the 24-29 amu cations. Furthermore, the comparable AEs of the 24-26 amu cations of pyridazine and pyrimidine support similar mechanisms for the formation of these cations in both molecules.

\subsubsection{Cations: $m=36-41 \mathrm{amu}$}

This is a mass region containing peaks of low intensity, which do not exceed a relative intensity of 3.0 (Tab. 2). In their high resolution studies, for mass $40 \mathrm{amu}$, Momigny et al. [11] reported two cations, $\mathrm{C}_{2} \mathrm{H}_{2} \mathrm{~N}^{+}$and $\mathrm{C}_{3} \mathrm{H}_{4}^{+}$, with intensities at $50 \mathrm{eV}$ in the ratio $3.5: 1$. The $\mathrm{C}_{2} \mathrm{H}_{2} \mathrm{~N}^{+}$may arise from dissociation of the parent cation into two fragments of equal masses, $\mathrm{C}_{4} \mathrm{H}_{4} \mathrm{~N}_{2}^{+} \rightarrow \mathrm{C}_{2} \mathrm{H}_{2} \mathrm{~N}^{+}+\mathrm{C}_{2} \mathrm{H}_{2} \mathrm{~N}$, which involves cleavage of the $\mathrm{N}(1)-\mathrm{N}(2)$ and $\mathrm{C}(4)-\mathrm{C}(5)$ bonds (see Fig. 1). The $\mathrm{C}_{3} \mathrm{H}_{4}^{+}$cations, on the other hand, would require hydrogen migration in the ring and breakage of, for example, $\mathrm{N}(2)-\mathrm{C}(3)$ and $\mathrm{C}(5)-\mathrm{C}(6)$ bonds to yield $\mathrm{C}_{4} \mathrm{H}_{4} \mathrm{~N}_{2}^{+} \rightarrow \mathrm{C}_{3} \mathrm{H}_{4}^{+}+\mathrm{CN}_{2}$. The 39 and 41 amu peaks correspond to cations originating from two analogue dissociation processes, $\mathrm{C}_{4} \mathrm{H}_{4} \mathrm{~N}_{2}^{+} \rightarrow \mathrm{C}_{2} \mathrm{HN}^{+}+\mathrm{C}_{2} \mathrm{H}_{3} \mathrm{~N}$ and $\mathrm{C}_{4} \mathrm{H}_{4} \mathrm{~N}_{2}^{+} \rightarrow \mathrm{C}_{2} \mathrm{HN}+\mathrm{C}_{2} \mathrm{H}_{3} \mathrm{~N}^{+}$, respectively, where, the positive charge is located interchangeably on the first or second fragment. In the above decomposition pathways of pyridazine the $\mathrm{N}(1)-\mathrm{N}(2)$ and $\mathrm{C}(4)-\mathrm{C}(5)$ bonds are broken and in addition hydrogen migration between the dissociation fragments should occur. The $39 \mathrm{amu}$ peak also contains contribution from the $\mathrm{C}_{3} \mathrm{H}_{3}^{+}$cations [11], which may originate from cleavage of, for example, $\mathrm{C}(5)-\mathrm{C}(6)$ and $\mathrm{N}(2)-\mathrm{C}(3)$ bonds. The 38 amu cations, which show two AEs at 14.3 and $17.8 \mathrm{eV}$ have been ascribed to $\mathrm{C}_{3} \mathrm{H}_{2}^{+}$ and $\mathrm{C}_{2} \mathrm{~N}^{+}$, as reported in [11], where their abundances at $50 \mathrm{eV}$ were in a ratio of 2:1. The 37 and 36 amu cations assigned to $\mathrm{C}_{3} \mathrm{H}^{+}$and $\mathrm{C}_{3}^{+}$, respectively, have higher AEs (Tab. 1) suggesting at multifragmentation processes in their appearance. We are aware, that the 43-45 amu mass peaks may contain some contamination cations and thus are difficult to assign.

\subsubsection{Cations: $m=12-15 \mathrm{amu}$}

This is a region containing the lightest $\mathrm{C}^{+}(m=12 \mathrm{amu})$, $\mathrm{CH}^{+}(m=13), \mathrm{CH}_{2}^{+} \quad(m=14)$ and $\mathrm{CH}_{3}^{+} \quad(m=15)$ cations originating from the decomposition of the pyridazine parent cations. The fact that they have higher AEs than those of most of the heavier cations points to more complex fragmentation pathways. The AEs of the 12 and 13 amu cations of 22.0 and $20.1 \mathrm{eV}$, respectively, are comparable to those of pyrimidine [1], which manifests analogous pathways.

\subsection{Total and partial cross sections}

The yield curves of the detected cations have been measured from their respective thresholds up to $140 \mathrm{eV}$. To obtain the absolute total ionization cross section, first the yield curves have been normalized to their abundances from Table 2 at $100 \mathrm{eV}$ and then have been summed. The total yield was next normalized to the computed cross section. Here, it was assumed that the measured cross section 


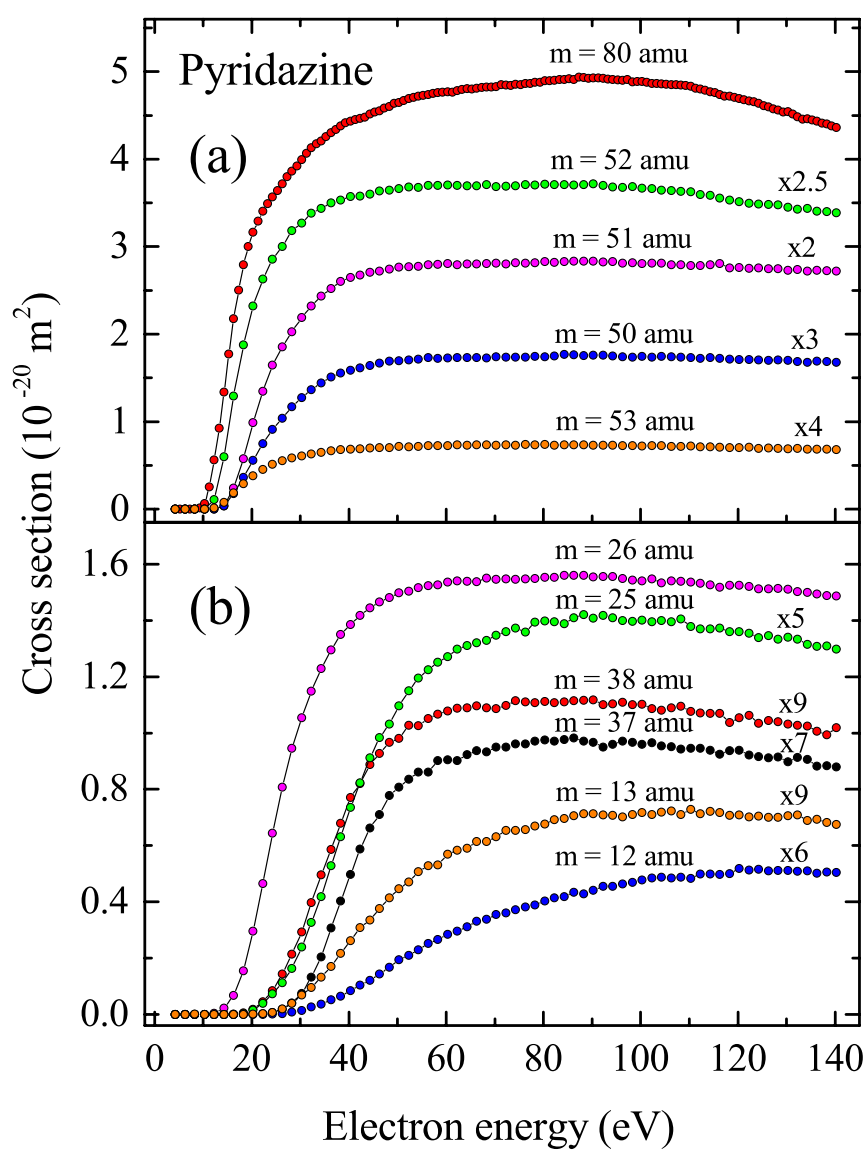

Fig. 5. The partial cross sections for ionization and fragmentation into the indicated cations of pyridazine.

should be equal in its maxim at $88 \mathrm{eV}$ to the calculated maximum of $12.72 \times 10^{-20} \mathrm{~m}^{2}$, which appears at slightly lower energy of $75 \mathrm{eV}$. This assumption seems to account for the fact that the measured ionization cross section carries, in addition, information on the cationic fragmentation processes, while the BEB calculated cross section only on the single ionization processes. The experimental and calculated cross sections of pyridazine are compared in Figure 4 in the electron energy range from the ionization threshold up to $140 \mathrm{eV}$; excellent agreement was achieved, within the experimental uncertainties, between shapes of both cross sections. The ionization cross section calculated in the whole energy range up to $4 \mathrm{keV}$ is shown in the inset of Figure 4, whereas the experimental cross section is listed in Table 3. In Figure 5a the absolute partial cross sections for the parent and heavier fragment cations are shown. Figure 5b displays the cross sections for pairs of lighter cationic fragments, which differ by loss of an hydrogen atom. In the assessment of the partial cross sections, the normalized total ionization cross section and abundances from Table 2 have been used. The uncertainty in the absolute value of the total ionization cross section is considered from the general consensus on the quality of the BEB calculations to be $\pm 15 \%$. The uncertainties in the partial cross sections can be estimated by further including the uncertainties in the cation abundances (Tab. 2).

\section{Conclusions}

The present work reports studies of the cation mass spectra and the cation fragmentation yield curves for pyridazine in the gas phase as well as determinations of the AEs and Wannier exponents for the observed cations. The mass peaks were detected in the mass range from 10 to 82 amu and assigned to the corresponding cations and cationic fragments. The cationic fragmentation processes of pyridazine were discussed. The AEs of the parent cation and of most of the cationic fragments were determined. The majority of these AEs were not reported previously.

The present work also reports on the calculations of the total cross section for ionization of pyridazine for energies from threshold up to $4 \mathrm{keV}$, using the BEB model. The calculated cross section was applied to normalize the cation total yield curve. The absolute total and partial ionization cross sections over the energy ranges from the respective ionization thresholds up to $140 \mathrm{eV}$ were obtained. Excellent agreement was achieved in the energy dependences between experimental and calculated cross sections. To our knowledge, the ionization cross sections in pyridazine are reported for the first time.

The present results for ionization and cationic fragmentation of pyridazine were compared with the corresponding results for pyrimidine obtained in our laboratory. The differences in the fragmentation processes of both molecules into the 50-53 amu mass cations were related to differences in the relative positions of the two nitrogen atoms in the structures of both molecular rings. On the other hand, close similarity in the shape and relative intensities of the mass peaks as well as comparable AEs of the cations in the 24-29 amu mass region indicate that the relative positions of both nitrogen atoms in the ring are not decisive in producing these cations.

Finally, when comparing the electron and proton impact mass spectroscopies close similarities are expected in the mass spectra measured for equivelocity electrons and protons for velocities higher than approximately $3 v_{0}$, where $v_{0}$ is the Bohr velocity. Such similarities have been observed by Wolff et al. [49] for pyrimidine ionization demonstrating weak dependence of the main fragmentation pathways on the ionizing projectile. Furthermore, the total and fragmentation cross sections for both projectiles tend to be equal in this velocity region [49]. The above similarities allow to transfer required spectroscopic information from electron to proton impact when, for example, evaluating effectiveness of hadrontherapy, which underlines demand for electron impact studies.

The authors gratefully acknowledge involvement of $\mathrm{T}$. Juchniewicz and W. Molicki in this project. Numerical calculations have been performed at the Gdańsk Academic Computer Center (TASK).

\section{Author contribution statement}

MD and MZ performed measurements and analysis of the data. PM performed computations. 
Open Access This is an open access article distributed under the terms of the Creative Commons Attribution License (http://creativecommons.org/licenses/by/4.0), which permits unrestricted use, distribution, and reproduction in any medium, provided the original work is properly cited.

\section{References}

1. I. Linert, M. Dampc, B. Mielewska, M. Zubek, Eur. Phys. J. D 66, 20 (2012)

2. N. Kishimoto, K. Ohno, J. Phys. Chem. A 104, 6940 (2000)

3. M.C. Fuss, L. Ellis-Gibbings, D.B. Jones, M.J. Brunger, F. Blanco, A. Munoz, P. Limão-Vieira, G. Garcia, J. Appl. Phys. 117, 214701 (2015)

4. M.U. Bug, W.Y. Baek, H. Rabus, C. Villagrasa, S. Meylan, A.B. Rosenfeld, Rad. Phys. Chem. 130, 459 (2017)

5. A.R. Bérces, P.G. Szalay, I. Magdó, G. Fogarasi, G. Pongor, J. Phys. Chem. 97, 1356 (1993)

6. A. Cartoni, A.R. Casavola, P. Bolognesi, M.C. Castrovilli, D. Cantone, J. Chiarinelli, R. Richter, L. Avaldi, J. Phys. Chem. A 122, 4031 (2018)

7. W. Akhtar, M. Shaquiquzzaman, M. Akhter, G. Verma, M.F. Khan, M. Alam, Eur. J. Med. Chem. 123, 256 (2016)

8. R.M. Butnariu, I.I. Mangalagiu, Bioorg. Med. Chem. 17, 2823 (2009)

9. K. Kusakabe et al. J. Med. Chem. 58, 1760 (2015)

10. W. Kim, H. Youn, T. Kwon, J. Kang, E. Kim, B. Son, H.J. Yang, Y. Jung, B.Youn, Pharmacol. Res. 70, 90 (2013)

11. J. Momigny, J. Urbain, H. Wankenne, Bull. Soc. Roy. Sci. Liège 34, 337 (1965)

12. M.H. Benn, T.S. Sorensen, A.M. Hogg, Chem. Commun. 1967, 574 (1967)

13. J.H. Bowie, R.G. Cooks, P.F. Donaghue, J.A. Halleday, H.J. Rodda, Aust. J. Chem. 20, 2677 (1967)

14. H. Ogura, S. Sugimoto, H. Igeta, T. Tsuchiya, J. Heterocycl. Chem. 8, 391 (1971)

15. NIST Chemistry WebBook, http://webbook.nist.gov/ chemistry

16. W. Wolff, H. Luna, E.C. Montenegro, J. Chem. Phys. 143, $044314(2015)$

17. L. Åsbrink, C. Fridh, B.Ö. Jonsson, E. Lindholm, Int. J. Mass Spectrom. Ion Phys. 8, 229 (1972)

18. G. Vall-Ilosera, M. Coreno, P. Erman, M.A. Huels, K. Jakubowska, A. Kivimäki, E. Rachlew, M. Stankiewicz, Int. J. Mass Spectrom. 275, 55 (2008)

19. L. Ellis-Gibbings, A.D. Bass, P. Cloutier, G. Garcia, L. Sanche, Phys. Chem. Chem. Phys. 19, 13038 (2017)

20. M. Dampc, T. Juchniewicz, W. Molicki, M. Zubek, in Abstracts of 2nd NANO-IBCT Conference, Gdańsk, Poland (2013), p. 74
21. R. Rejoub, B.G. Lindsay, R.F. Stebbings, Phys. Rev. A 65, $042713(2002)$

22. T.D. Märk, J. Chem. Phys. 63, 3731 (1975)

23. S. Matt et al. Chem. Phys. Lett. 264, 149 (1997)

24. M. Dampc, I. Linert, M. Zubek, J. Phys. B 48, 165202 (2015)

25. Y.-K. Kim, M.E. Rudd, Phys. Rev. A 50, 3954 (1994)

26. W. Hwang, Y.-K. Kim, M.E. Rudd, J. Chem. Phys. 104, 2956 (1996)

27. Y.-K. Kim, W. Hwang, N.M. Weinberger, M.A. Ali, M.E. Rudd, J. Chem. Phys. 106, 1026 (1997)

28. G.P. Karwasz, P. Możejko, M.-Y. Song, Int. J. Mass Spectrom. 365-366, 232 (2014)

29. H. Tanaka, M.J. Brunger, L. Campbell, H. Kato, M. Hoshino, A.R.P. Rau, Rev. Mod. Phys. 88, 025004 (2016)

30. M.J. Frisch et al. Gaussian 09, Revision D.01 (Gaussian Inc., Wallingford, CT, 2013)

31. L.S. Cederbaum, J. Phys. B 8, 290 (1975)

32. W. von Niessen, J. Schirmer, L.S. Cederbaum, Comp. Phys. Rep. 1, 57 (1984)

33. J.V. Ortiz, J. Chem. Phys. 89, 6348 (1988)

34. V.G. Zakrzewski, W. von Niessen, J. Comp. Chem. 14, 13 (1994)

35. O. Mó, J.L.G. de Paz, M. Yáñez, J. Mol. Struct. (Theochem) 150, 135 (1987)

36. K.-W. Choi, D.-S. Ahn, J.-H. Lee, S.K. Kim, J. Phys. Chem. A 110, 2634 (2006)

37. A. Almenningen, G. Bjornsen, T. Ottersen, R. Seip, T.G. Strand, Acta Chem. Scand. A 31, 63 (1977)

38. S. Cradock, C. Purves, D.W.H. Rankin, J. Mol. Struct. 220, 193 (1990)

39. M.H. Palmer, I.C. Walker, Chem. Phys. 157, 187 (1991)

40. J.V. Ortiz, V.G. Zakrzewski, J. Chem. Phys. 105, 2762 (1996)

41. D.M.P. Holland, D.A. Shaw, S. Coriani, M. Stener, P. Decleva, J. Phys. B 46, 175103 (2013)

42. R. Gleiter, E. Haibronner, V. Hornung, Helv. Chim. Acta 55, 255 (1972)

43. T. Fiegele, G. Hanel, I. Torres, M. Lezius, T.D. Märk, J. Phys. B 33, 4263 (2000)

44. A.J. Yencha, M.A. El-Sayed, J. Chem. Phys. 48, 3469 (1968)

45. R. Buff, J.Dannacher, Int. J. Mass Spectrom. Ion Process. 62, l (1984)

46. P. Plessis, P. Marmet, Int. J. Mass Spectrom. Ion Process. 70, 23 (1986)

47. C. Tian, C.R. Vidal, J. Phys. B 31, 895 (1998)

48. Z. Li, M.M. Dawley, I. Carmichael, S. Ptasińska, Int. J. Mass Spectrom. 410, 36 (2016)

49. W. Wolff, H. Luna, L. Sigaud, A.C. Tavares, E.C. Montenegro, J. Chem. Phys. 140, 064309 (2014) 